REVISTA X, volume12, n.1, p107-120, 2017

\title{
ESTRATÉGIA DISCURSIVA DA REVISTA VEJA EM UM ARTIGO DE OPINIÃO SOBRE EDUCAÇÃO
}

\author{
The Discursive Strategy of Revista Veja in an Opinion Article on Education
}

Tânia Cristina Apolinário SANTOS - UNITAU ${ }^{1}$

Geraldo Sávio Fonseca ALMEIDA - UNITAU ${ }^{2}$

\begin{abstract}
RESUMO: Neste trabalho são apresentados dados de uma pesquisa, inserida no campo da Linguística Aplicada, cuja análise objetivou identificar a importância dos meios de comunicação na formação da opinião pública, nas decisões e nas concepções que circulam o mundo. Especificamente, a pesquisa buscou verificar a estratégia discursiva da Revista Veja, em um artigo de opinião, apontando os recursos argumentativos empregados pelo articulista. Utilizamos como corpus um artigo de opinião, escrito pelo colunista Cláudio Moura Castro, que aborda o papel do professor, em especial, sua remuneração, publicado em 27 de julho de 2016. Como suporte à análise do objeto, utilizamos os pressupostos teóricos acerca das concepções de dialogismo e ideologia bakhtinianos, a fim de desvelar concepções implícitas de linguagem e de ideologia no discurso midiático. Os resultados mostraram que as contradições e os conflitos são marcas do discurso jornalístico, que nos mobilizam a refletir até que ponto o que a mídia traz traduz a realidade. A análise dos dados mostrou que a Revista Veja estabelece com seu leitor imaginado uma relação paradoxal: por um lado, imagina-o como um leitor articulado, com bom nível de compreensão do mundo; por outro, imagina-o como um leitor ingênuo, cuja opinião deve ser construída pelos jornalistas.
\end{abstract}

PALAVRAS-CHAVE: Educação; Professor; Valorização; Salário; Revista Veja

ABSTRACT: In this paper, we present data of a research in the field of Applied Linguistic, and the analysis aimed to identifying the importance of the means of communication for the public opinion formation, decisions and conceptions circulating throughout the world. Specifically we have attempted to verify the discursive strategy of Revista Veja in an article published on 27 July 2016, discussing the role of teachers, specially their remuneration, pointing out the argumentative resources employed by the writer. In order to achieve the proposed aims, we have used as corpus an article written by the columnist Cláudio de Moura Castro as well as some theoretical assumptions concerning Bakhtin's concepts of dialogism and ideology were observed with the purpose of revealing language implicit conceptions and ideology on the media discourse. The results show that the contradictions and the conflicts are characteristics of the journalistic discourse which might lead us to reflect on to what extend the media represent the reality. The data have shown that Revista Veja established with its imaginary reader a paradoxical relationship: in one hand sees this reader as a critical

1 Mestranda em Linguística Aplicada pela UNITAU; docente do Ensino Fundamental II, de Língua Portuguesa da Rede Municipal de Ensino de Campos do Jordão.

2 Mestrando em Linguística Aplicada pela UNITAU; docente de Língua Portuguesa e Língua Inglesa da Rede Pública do Estado da Bahia. 
one, with a great level of comprehension of the world, but on the other hand also sees him/her as a naïve, which opinion tend to be constructed by journalists.

KEY WORDS: Education; Teacher; Appreciation; Salary; Revista Veja

\section{INTRODUÇÃO}

Atualmente, o papel da educação e, principalmente, da escola merece destaque em todos os campos sociais, no Brasil, e a mídia tem utilizado amplamente essa temática, tentando refletir a escola atual e a "escola ideal". Considerando o discurso como um "local" privilegiado para a disputa hegemônica e que as relações sociais estão cada vez mais mediadas e midiatizadas, é extremamente importante que analisemos os discursos que circulam na mídia nacional, nos dias atuais.

O presente trabalho tem como objetivo, portanto, mostrar como a educação e o papel do professor aparecem na produção discursiva de um artigo de opinião escrito pelo colunista Cláudio de Moura Castro e publicado em 27 de julho de 2016, na Revista Veja, uma das principais revistas brasileiras da atualidade, com circulação nacional e maior tiragem registrada em sua categoria.

O que justifica a necessidade de uma análise do discurso de uma revista de grande circulação nacional é a forma como as opiniões são tratadas por esse meio de comunicação, demonstrando a sua "verdade" sobre fatos que nem sempre correspondem à realidade. A partir da análise desse artigo de opinião, que aborda a educação, e, em especial, o papel dos professores, buscamos compreender e mostrar como as relações de poder das políticas neoliberais tornam-se práticas insidiosas, incorporadas nos discursos deste tipo de publicação, sem uma conotação repressora e autoritária, mas como verdades que circulam nos espaços públicos, interagindo produtivamente com os leitores e leitoras das revistas semanais de notícias.

O jornalismo é um lugar de circulação e produção de sentidos. Convém, portanto, afirmar suas principais características: é um discurso dialógico, polifônico, opaco, efeito e produtor de sentidos, elaborado segundo regras e rotinas particulares. É dialógico, pois existe apenas na relação entre sujeitos (BAKHTIN, 2014) e deve ser pensado em função dos sujeitos que o envolve.

É por natureza polifônico, pois supõe pluralidade de vozes e deve ser avaliado segundo a configuração dessa polifonia: ela é real ou mera aparência? Embora se apresente como um discurso transparente é, na verdade, opaco, pois contém diversas possibilidades de interpretação e nem sempre deixa ver seu enunciador, além de não 
permitir que se visualizem suas condições de produção e os interesses de quem enuncia. É efeito e produtor de sentidos, pois, se por um lado deriva da fala de indivíduos inseridos historicamente em seu tempo, sendo efeito dos sentidos dominantes nesses contextos, por outro tem o poder de nomear, consagrando ou ocultando sujeitos, políticas, instituições, práticas e ideologias.

De acordo com Benetti,

um gênero é uma moldura onde se podem enquadrar determinados textos. Não é uma imposição externa, e sim uma espécie de acordo que vai se firmando entre quem fala e quem lê, um acordo que cumpre funções e respeita expectativas, um acordo tácito, entre quem escreve e quem lê, sobre as regras daquele texto, segundo os dispositivos de enunciação definidos também pelo suporte em que esse texto produz sentidos (BENETTI, 2007, p).

Para esta autora, no caso do jornalismo, falamos de um acordo entre o jornalista e o leitor sobre o que é o jornalismo, o que pode ser dito (e o que não pode ser dito), o lugar reservado ao leitor, o papel que o jornalista deve exercer e o tipo de informação que deve entregar. Este não é um acordo recente, estabelecido por um veículo ou um jornalista em particular. É um contrato de leitura que define um gênero discursivo, o gênero do discurso jornalístico, construído ao longo de pelo menos quatro séculos (BENETTI, 2007).

A base do contrato de leitura entre jornalistas e leitores é a noção de que o jornalismo é um discurso comprometido com a verdade. O discurso jornalístico amparase, assim, em algumas ilusões: a) o jornalismo retrata a realidade como ela é; b) tudo que é de interesse público assim é tratado pelo jornalismo; c) o compromisso com a verdade não se subordina a nenhum outro interesse; d) o jornalismo ouve a melhores fontes, e as fontes oficiais costumam ser as mais confiáveis; e) os melhores especialistas são aqueles que falam na mídia; f) todos que têm algo relevante a dizer têm espaço no jornalismo dito sério ou de referência; g) jornalismo e propaganda não se confundem (BENETTI, 2007).

Sendo assim, estabelecemos como foco principal nesse texto, discutir a maneira como a Revista Veja estrutura o discurso sobre o papel do professor no ambiente escolar e a importância, ou pouca importância, do valor econômico atribuído ao seu trabalho. Ao refletir sobre a formação inicial e continuada de professores, a análise sobre o discurso da revista ganha relevância, tendo em vista que interage com a maneira como os docentes percebem e contextualizam tempos e espaços. 
Segundo as Diretrizes Curriculares Nacionais para a Formação de Professores da Educação Básica,

\begin{abstract}
de um modo geral, os cursos de formação eximem-se de discutir padrões éticos decorrentes da disseminação da tecnologia e reforçam atitudes de resistência, que muitas vezes, disfarçam a insegurança que sentem os formadores e seus alunos-professores em formação, para imprimir sentido educativo ao conteúdo das mídias, por meio da análise, da crítica e da contextualização, que transformam a informação veiculada, massivamente, em conhecimento. (BRASIL, 2001, p. 25)
\end{abstract}

Neste trabalho, são apresentados dados de uma pesquisa, inserida no campo da Linguística Aplicada, cuja análise objetivou identificar a importância dos meios de comunicação na constituição da opinião pública, e, especificamente, buscou verificar a estratégia discursiva da revista em questão, em um artigo de opinião, apontando os recursos argumentativos empregados pelo articulista.

Para alcançar os objetivos propostos, tomamos como corpus um artigo que abordava o papel do professor, em especial, sua remuneração, escrito pelo colunista Cláudio de Moura Castro e publicado em 27 de julho de 2016, em uma das maiores revistas brasileiras, autodenominada informativa: a Veja. A pesquisa, preocupada com a falta de base sobre os dados mencionados pelo autor do artigo de opinião, procura discutir a produtividade política da articulação neoliberal na revista, já que ao mesmo tempo em que ela é produzida, também cria práticas e subjetividades férteis para a sua execução.

\title{
2 FUNDAMENTAÇÃO TEÓRICA
}

Dentre os conceitos bakhtinianos mencionamos dois aspectos que consideramos relevantes a esta pesquisa: o dialogismo e a ideologia. A análise do artigo de opinião utilizado como corpus busca identificar uma relação dialógica e ideológica, baseada nas opiniões emitidas pelo colunista Castro, e a sua maneira de perceber o trabalho do professor. A concepção de linguagem em Bakhtin se fundamenta num caráter dialógico.

Para ele, todo enunciado faz parte de um diálogo, portanto, de um processo de comunicação ininterrupto, assim definindo-o:

O diálogo, no sentido estrito do termo, não constitui, é claro, senão uma das formas, é verdade, que das mais importantes, da interação verbal. Mas pode-se compreender a palavra "diálogo" num sentido amplo, isto é, não apenas como a comunicação em voz alta, de 
pessoas colocadas face a face, mas toda comunicação verbal, de qualquer tipo que seja (BAKHTIN, 2014, p. 127).

Quando se diz que o dialogismo é constitutivo do enunciado, está se afirmando que, em sua estrutura composicional, as diferentes vozes se manifestam, ou seja, todos os enunciados constituem-se a partir de outros. Sendo assim, o dialogismo pode e deve ser considerado como relações de sentido que se estabelecem entre dois enunciados. Em outras palavras, o enunciador, para constituir um discurso, leva em conta o discurso de outrem, que está presente no seu. Assim sendo, todo discurso é inevitavelmente ocupado pelo discurso alheio.

Logo,

dois enunciados distantes um do outro, tanto no tempo quanto no espaço, que nada sabem um sobre o outro, no confronto dos sentidos revelam relações dialógicas se entre eles há ao menos alguma convergência de sentidos (ainda que seja uma identidade particular do tema, do ponto de vista, etc.) (BAKHTIN, 2015, p. 331).

Desse modo, o dialogismo é, para Bakhtin, o princípio que norteia a vida discursiva e marca sua presença no enunciado. Todavia, não reduz a comunicação interpessoal, entre locutores e ouvintes, mas pressupõe também relações com enunciados anteriores. O dialogismo, portanto, afeta o discurso por fora e por dentro, não apenas constituindo os elos entre os interlocutores, mas participando da vida interna do discurso e conduzindo as vozes sociais que o compõem. Nessa perspectiva, o diálogo, tanto exterior, na relação com o outro, como no interior da consciência, ou escrito, realiza-se na linguagem.

Assim, Bakhtin (2015) define relação dialógica como

o novo tipo de relações semânticas, cujos membros só podem ser enunciados integrais (ou vistos como integrais ou potencialmente integrais), atrás dos quais estão (e nos quais exprimem a si mesmos) sujeitos do discurso reais ou potenciais, autores de tais enunciados) (BAKHTIN, 2015, p. 330/331).

Ou seja, quaisquer enunciados que são confrontados em um plano de sentido, que não objetivo, nem tampouco exemplos linguísticos, acabam em relação dialógica.

Já a ideologia é um conceito primordial nos estudos realizados por Bakhtin acerca da linguagem. Seus estudos sobre a ideologia fundamentavam-se em uma perspectiva marxista, porém, ele buscava quebrar essa tradição de análise ideológica 
como subjetiva e interiorizada, que entendia a ideologia como ideia estática, idealista, que se desenvolvia no interior intelectual do sujeito. Não podendo ser compreendida, assim, como acontecimento vivo e dialógico.

Conforme Bakhtin (2005),

A linguagem só vive na comunicação dialógica daqueles que a usam. É precisamente essa comunicação dialógica que constitui o verdadeiro campo da vida da linguagem. Toda a vida da linguagem seja qual for o seu campo de emprego (a linguagem cotidiana, a prática, a científica, a artística, etc.), está impregnada de relações dialógicas (BAKHTIN, 2005, p. 183).

Sendo assim, o conjunto de signos de um grupo social constitui o que Bakhtin chama de universo de signos, ou seja, além do sentido físico-material e sócio-histórico, ele recebe significações de um dado sujeito, determinando a realidade, logo tornando-se o signo ideológico. O lugar dessa materialização do signo é na comunicação contínua, e se dá na interação verbal constituindo a linguagem como o lugar mais claro e completo da materialização do fenômeno ideológico.

Bakhtin (2014, p. 31) deixa claro que "tudo que é ideológico possui um significado e remete a algo situado fora de si mesmo. Em outros termos, tudo que é ideológico é um signo. Sem signos não existe ideologia”. Bakhtin coloca como base de sua teoria a enunciação, esta vista como realidade da língua e como estrutura social e ideológica. Logo, o signo e a situação social estão ligados; assim os sistemas semióticos servem para retratar a ideologia.

Apoiando-se no pensamento de Bakhtin, Miotello (2014, p.172) afirma que "o signo verbal não pode ter um único sentido, mas possui acentos ideológicos que seguem tendências diferentes, pois nunca consegue eliminar totalmente outras correntes ideológicas de dentro de si”.

Seguindo essa perspectiva, as formações ideológicas podem ser entendidas como representações, ideias de um determinado grupo social que revelam a compreensão de uma dada classe, e essas formações correspondem a uma formação discursiva que materializam uma dada visão de mundo. E o homem constrói seus discursos assimilando essas formações, por isso dizemos que esses discursos são mais reproduzidos que construídos. 
A ideologia está submersa no objeto, no social, não estando, portanto, somente na consciência. Ela existe mesmo sem a consciência dos sujeitos sociais, ocultando, de uma forma fenomênica, a realidade e suas relações mais profundas, expressando-se de uma maneira invertida. Essa inversão caracteriza-se como ideologia. A forma como uma classe social percebe a realidade e a ordena torna-se um fator ideológico.

O jornalismo, ao se apresentar como objetivo e neutro, posiciona-se como uma instituição que estaria autorizada a retratar a realidade. A linguagem, porém, nada tem de ingênua (ORLANDI, 2001, 2004) e não é um mero operador instrumental. A linguagem é, sim, um poderoso eixo de legitimação de autoridade. Se o jornalismo compreende a si mesmo como uma autoridade capaz de narrar e retratar o cotidiano e inscreve essa autoridade no contrato que assina com o leitor, acaba por criar uma forte relação de poder totalmente assimétrica.

A relação eu/tu é condição para a existência do discurso, é nessa reversibilidade que o dizer se estabelece. É o que faz o jornalista acreditar que "conhece" seu público, já que "[...] se pode falar de outros para falar de si, pode-se falar de si para falar de outros e pode-se falar de si para falar de si" (ORLANDI, 1988, p. 15).

\section{A REVISTA VEJA}

Atualmente, a revista Veja é considerada um fenômeno editorial no país, tanto em números de leitores como na definição da agenda de debates na sociedade. A revista faz um jornalismo diferente daquele praticado nos jornais diários. Diferindo-se do jornal, que possui um público heterogêneo, a revista atinge um grupo de leitores mais homogêneo e com interesses em comum.

Produzida pela Editora Abril, é a revista semanal de informação com maior tiragem do país. Lançada em 1968, Veja atingiu certa estabilidade apenas em meados dos anos 1970 (VILLALTA, 2002). Sendo a principal revista de informação do Brasil, e uma poderosa formadora de opinião, tem merecido nos últimos tempos a atenção de pesquisadores, e os intrigado consideravelmente, no que diz respeito à sua capacidade de produção de sentidos.

Inserida em um contexto de formação de opinião que demanda estudos aprofundados, Veja não se enquadra nos gêneros tradicionais de texto jornalístico, notadamente na distinção entre jornalismo informativo e opinativo. Embora carregado de informação, seu texto é fortemente permeado pela opinião, construída principalmente 
por meio de adjetivos, advérbios e figuras de linguagem. Veja construiu, de si mesma, uma forte imagem de legitimidade para proferir saber - frente a um suposto não-saber dos leitores, da população em geral e, em certos momentos, das próprias fontes.

Dessa forma, a revista sempre buscou o seu público específico, tratando os assuntos de maneira mais aprofundada do que os jornais diários e de forma mais atrativa possível para chamar a atenção e interesse do leitor, e dá um tratamento especial em suas páginas, aos recursos infográficos (gráficos, tabelas, fotos, ilustrações, mapas, desenhos, etc.) para que elas (as páginas) se tornem mais sedutoras.

Em sua produção discursiva, a revista propõe a estabelecer com seu leitor uma relação de lealdade e de confiança e, para isso, intitula a credibilidade como sendo o seu maior patrimônio. Seu discurso afirma compromisso de ser vigilante e investigativa, e manter-se atenta a tudo e a todos que gerem interesse ao seu público. Esses são compromissos sempre reafirmados para o leitor: "Permanecem os compromissos históricos de Veja com a democracia e a economia de mercado e, perante seus leitores, com a qualidade, a inteligência e a integridade da informação" (VEJA, 2016, p. 10).

\section{PROFESSOR GANHA MAL?}

“Professor ganha mal?" é o título de um artigo publicado na Revista Veja, em 27 de julho de 2016 (anexo 1) e expressa opiniões distorcidas e tendenciosas em torno do significado do papel do professor na sociedade brasileira atual. O discurso jornalístico analisado recorre, de forma proeminente, à ideia de que o professor ganha bem, considerando as horas "trabalhadas", onera os cofres públicos e aposenta-se cedo. O professor tem, nesse discurso, privilégios, segundo Claudio de Moura Castro, autor do artigo mencionado.

Iniciaremos nossa análise pelo título do texto, que está em forma de pergunta: “Professor ganha mal?", que o autor não responde com números, ao longo de todo o texto. Provavelmente, pelo fato do autor ter conhecimento de que seus leitores, de classe média alta, ficariam espantados com os referidos valores. Mesmo quando, no segundo parágrafo, o autor tenha reconhecido as complexidades de se discutir o salário do docente, em nenhum momento cita os números.

Quando afirma que "O salário inicial no Rio é maior que o de outras profissões", Castro não diz o valor desse salário, quais são essas profissões a que ele se refere e quanto elas recebem. Parece desconhecer um estudo publicado com dados do IBGE e 
PNAD, que afirma que professores ganham em média metade do que ganham seus colegas de outras profissões com escolaridade semelhante.

O autor apresenta ainda vários dados incoerentes que confundem o leitor, quando menciona indevidamente que "não há relação clara entre o salário do professor e o que aprendem os alunos", para apontar uma possível relação causal (dos números que ele não informa), entre salário do docente e notas de algum teste (que ele também não menciona - provavelmente refira-se ao IDEB), usando como exemplo os estados do Amapá e Minas Gerais.

Mesmo com pouco conhecimento em estatísticas, percebemos que não é possível fazer essa correlação, pois não foram isoladas as duas variáveis. Não há relações entre os alunos, as escolas, os professores, os investimentos e as famílias dos estados do Amapá e de Minas Gerais. As variáveis são muitas, e assim não podemos realizar uma correlação entre o salário docente e notas dos alunos em testes de larga escala.

No parágrafo seguinte, Castro escreve uma sequência de frases sem dados, só com "grandes verdades": "Os salários são até competitivos", "Em termos internacionais gastamos bastante"... E mais uma vez não menciona os números a que se referem. Que salários? Competitivos em relação a quê? Internacionalmente gastamos com o quê em relação a quem? Desta forma, sem fornecer essas informações relevantes na formação da opinião pública, vamos demonstrar o erro primordial do parágrafo: ao compararmos internacionalmente investimentos em educação necessitamos de dados específicos, para não incorrermos ao despropósito de compararmos o investimento total do Brasil com educação, com outros países que possuem uma realidade totalmente diferente da nossa.

Temos também que considerar o crescimento/envelhecimento da população, pois países com população envelhecendo terão cada vez menos alunos, o que diminui a despesa com educação. Países em que a população aumenta, consequentemente, haverá mais crianças em idade escolar e necessita de novas escolas e ampliar a contratação de professores; o que, naturalmente, gera uma previsão de gastos maiores para a educação.

No restante do texto, o autor só traz elucubrações acerca do professor e sua carreira, como se fosse uma profissão fácil e com muitos benefícios. Castro chega ao ponto de questionar direitos trabalhistas, comuns a qualquer trabalhador. Além de descontar férias do período trabalhado, chegando ao cálculo de que o professor trabalha de 11,5 anos na sala de aula, mencionando-os como "seleto grupo", fica evidente sua intenção de colocar o leitor "contra o professor". 
Castro posiciona-se em todo o texto através da utilização de adjetivos e evidencia-se na cena enunciativa ao expressar a sua opinião em relação aos fatos. $\mathrm{O}$ propósito comunicativo ressalta do contexto da enunciação, sendo o leitor conduzido ao convencimento através do encadeamento dos argumentos. Demonstra uma certa discriminação entre os professores, principalmente ao afirmar "Há a injustiça dos ótimos ganhando o mesmo que os péssimos", evidenciando o ideológico. Notamos a ideologia da meritocracia, o que estimularia o aumento da produtividade e da eficiência do trabalho docente.

O articulista, no último parágrafo, ao fazer perguntas aos professores: “...é esse o sistema que vocês querem? E, se não é, por que não reclamam? Por que não se queixam aos sindicatos?" Observamos a presença da ideologia fortemente acentuada pela desigualdade de tratamento entre os discentes tão presente em nosso país.

Podemos, entretanto, questionar se a forma como o professor é visto e legitimado pelo discurso jornalístico da revista Veja interessa a todos. É necessário observar que o discurso sobre o papel do professor, de sua remuneração e de seu desempenho esconde mais do que mostra como efetivamente funciona a sociedade capitalista globalizada. As contradições e os conflitos são marcas do discurso jornalístico que nos mobilizam a refletir até que ponto o que a mídia traz traduz a realidade.

Sendo assim, a partir da concepção bakhtiniana, cada texto é produzido em um dado momento sócio-histórico com um determinado objetivo, o qual, no caso do texto opinativo pode ser o de persuadir o leitor sobre um determinado ponto de vista. Desta forma, o processo de construção do sentido de um texto envolve muitos fatores que vão além da simples materialização do texto.

\section{CONCLUSÕES}

Neste trabalho, não procuramos produzir a verdade, até mesmo porque as verdades podem ser muitas, dependendo de como é a perspectiva do olhar lançado sobre a realidade. Procuramos examinar o discurso jornalístico e seu funcionamento; uma reflexão possível, construída a partir de um determinado percurso teórico-metodológico.

O discurso jornalístico não é homogêneo, pelo contrário, em muitos momentos se mostra contraditório e expõe os seus equívocos, seus limites e heterogeneidades. Em muitos momentos, ele se trai e transparece outros sentidos que podem ser contraditórios 
com as defesas e promessas que faz ao leitor. Isto se tornou evidente em nosso trabalho, quando analisamos as enunciações sobre o professor, sua carreira, e o resultado do seu trabalho.

Com muita frequência, a mídia se autoelogia e demonstra o seu poder e eficiência para ensinar os cidadãos a entender o mundo, a saber agir como ser, e o que fazer diante dos desafios a que a atualidade nos expõe. No discurso jornalístico brasileiro contemporâneo, então, percebe-se a tendência de se afirmar que a educação no Brasil, sobretudo, no sistema público, é de péssima qualidade e que a escola é anacrônica, enfadonha e não consegue dar respostas às exigências da formação das crianças e dos jovens de hoje. Esse discurso dominante na mídia produz uma imagem negativa dos professores, sobre sua formação e a competência para ensinar acerca do mundo. Inclusive, parece colocar a culpa no professor pela situação da educação atual.

Percebemos, durante todo o processo, que o discurso é um grande campo de manifestação do sujeito, tornando-se um mecanismo de plena participação social nos diferentes grupos e em distintos momentos de sua história. Pela linguagem expressamos ideias, pensamentos e intenções, estabelecemos relações interpessoais anteriormente inexistentes, influenciando o outro e alterando suas representações da realidade e suas (re) ações, bem como, construímos concepções e orientações ideológicas.

Nessa perspectiva, Bakhtin (2015) demonstra que "o homem entra no diálogo como voz integral. Participa dele não só com seus pensamentos, mas também com seu destino, com toda a sua individualidade" (p. 349). É o que faz Castro, portanto, ao construir seu discurso, em que coloca toda sua singularidade, e acaba por estabelecer relações dialógicas com outros discursos, dentro de uma visão bakhtiniana.

O estilo de Veja faz um duplo e importante movimento nesse jogo de linguagem. Por um lado, fortalece a opinião da revista sobre certas práticas, pessoas ou lugares, e por outro lado, estabelece com o leitor uma relação de cumplicidade interpretativa. $\mathrm{O}$ sentido geral que a revista tenta estabelecer é algo como "eu digo o que penso, e o que penso é que isto é tão imoral ou ridículo, que obviamente você, leitor, não pode discordar de mim, pois você não é imoral ou ridículo (ou é?)” (BENETTI, 2007).

Vale lembrar, porém, que essa é a uma estratégia discursiva e carrega seus próprios riscos. Exige que jornalista e leitor partilhem conhecimentos, e nem sempre esses conhecimentos estão assegurados pelo próprio texto - nesse caso, ela pode simplesmente não funcionar, porque pode criar ao redor de quem fala uma aura de arrogância e prepotência, principalmente quando a opinião de quem fala não se coaduna 
com a opinião de quem lê, já que os leitores podem ter sua própria opinião a respeito do que está sendo "julgado".

Em outras palavras, o que se pode perceber é que Veja estabelece, com seu leitor imaginado, uma relação paradoxal: por um lado, imagina-o como um leitor articulado, com bom nível de compreensão do mundo e da própria linguagem; por outro, imagina-o como um leitor ingênuo, cuja opinião deve ser construída pelos jornalistas.

A análise dos dados desta pesquisa mostra-nos, portanto, o poder da Revista Veja como formadora de opinião, assim como o seu poder de transmitir as notícias demonstrando a sua "verdade" sobre fatos que nem sempre podem corresponder à realidade. Sua estratégia discursiva deve ser, portanto, analisada e estudada por outros pesquisadores, para que possamos melhor compreender a força dessa estratégia discursiva. Esperamos, então, que este trabalho tenha dado alguma contribuição nesse sentido.

\section{REFERÊNCIAS}

BENETTI, M. A ironia como estratégia discursiva da revista Veja. Revista Líbero, São Paulo, ano X, no 20, Dez. 2007

BAHKTIN, M. Problemas da Poética de Dostoiévski. 3. ed. Rio de Janeiro: Forense Universitária, 2005.

. Marxismo e filosofia da linguagem. 16. ed. São Paulo: Hucitec, 2014.

Estética da criação verbal. 6. ed. São Paulo: Martins Fontes, 2015.

BRASIL, Conselho Nacional de Educação. Diretrizes Curriculares Nacionais para a Formação de Professores da Educação Básica, em Nível Superior, Curso de Licenciatura de Graduação Plena. Brasília, DF, 05/08/2001. Relatório.

MIOTELLO, V. Ideologia. In: BRAIT, Beth (org.). Bakhtin: conceitos-chave. 5. ed. São Paulo: Contexto, 2014.

ORLANDI, E. A incompletude do sujeito: e quando o outro somos nós?. In: ORLANDI, Eni (org.). Sujeito e texto. São Paulo: EDUC, 1988.

Análise de discurso: princípios e procedimentos. 3. ed. Campinas: Pontes, 2001.

Interpretação: autoria, leitura e efeitos do trabalho simbólico. 4. ed. Campinas: Pontes, 2004.

REVISTA VEJA. Ed. 09 de Março de 2016. São Paulo: Abril editora, 2016. 
Ed. 27 de Julho de 2016. São Paulo: Abril editora, 2016.

TODOS pela educação. Gráficos do PNE. Disponível em: http://www.observatoriodopne.org.br/

VILLALTA, D. O surgimento da revista Veja no contexto da modernização brasileira. Anais do XXV Congresso Brasileiro de Ciências da Comunicação. CD-ROM. Salvador, 2002. Disponível em: https://pt.wikipedia.org/wiki/Claudio_de_Moura_Castro

\section{ANEXOS}

Anexo 1 - Artigo publicado na revista Veja, em 27 de julho de 2016

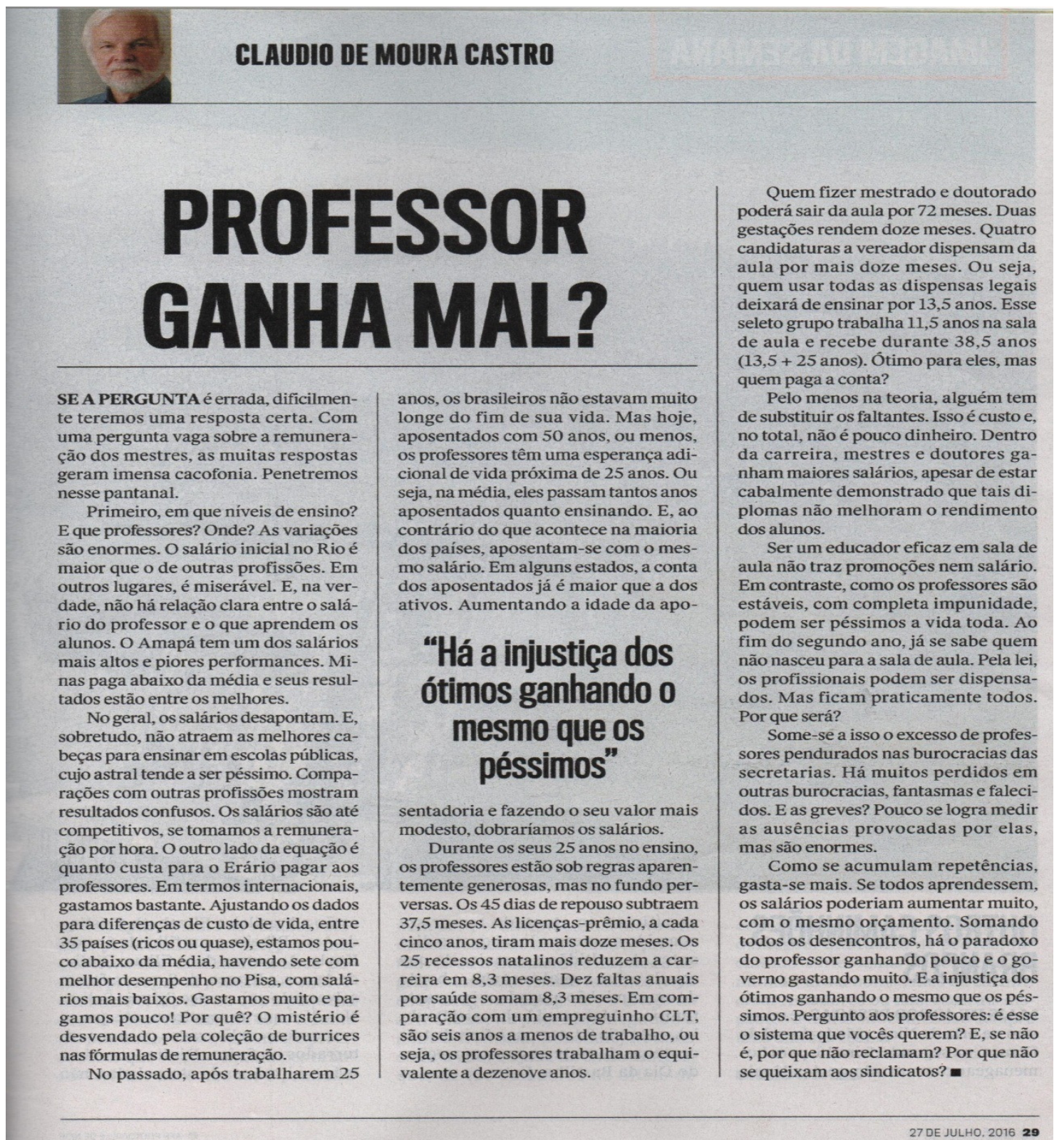

Anexo 2 - Quadro informativo IBGE - Todos Pela Educação 
REVISTA X, volume12, n.1, p107-120, 2017

Rencimento médio dos professores de Educação Básica em relação ao rendimento médio dos demais profissionais com mesma escolaridade

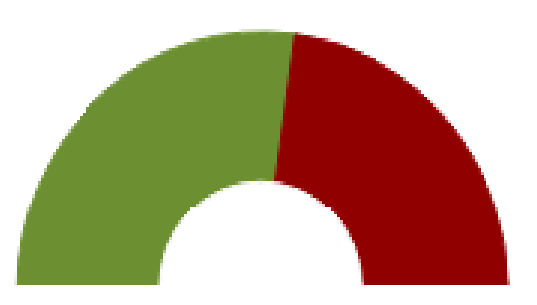

Atual (2014)

$54,5 \%$

Meta (2020)

$100 \%$

Fonte: IBGE/Pnad

Elaboração: Todos Pela Educação 